\title{
International Institute of Cellular and Molecular Pathology
}

\section{Christian de Duve, M.D., Ph.D., Founding Administrator}

The International Institute of Cellular and Molecular Pathology (ICP) opened its doors in 1974 on the new campus of the Medical Faculty of the Université Catholique de Louvain (UCL) in Woluwé-Saint-Lambert, on the outskirts of Brussels. At that time, it was one of the first of a new generation of institutions devoted to what has come to be known as biomedical research, designed to exploit the recent advances in basic biology for the benefit of human health.

Symbiotically located within the UCL Medical Faculty, the ICP houses several of the Faculty's research laboratories and has access to all its facilities, including the library, animal building, and cafeteria, so that most of the ICP's 8,000 square meter area can be devoted to research. The ICP collaborates with other laboratories on campus and keeps close ties with the 900-bed university hospital. At the same time, the ICP is a legally autonomous institution, with its own board of directors and the ability to appoint staff, apply for grants, sign contracts, raise funds, and receive tax-deductible gifts and bequests. Especially, it has the freedom to chart its own course, taking full advantage of its academic setting while not being necessarily subject to the university's inherent constraints. Thanks to this status, the core provided by the Medical Faculty has been strengthened by a number of additional research groups, including the Brussels Branch of the Ludwig Institute for Cancer Research (LICR), which is an international organization based in Zurich, with branches in several parts of the world. Entirely funded by the LICR as an independent unit within the ICP, but working in close cooperation with ICP groups, this branch has expanded considerably and now occupies about one-third of the Institute laboratory space. It is headed by Professor Thierry Boon, who is also the chairman of the ICP directorate.

The internal organization of the ICP is inspired by a number of guiding principles:

1. Priority to basic research, in keeping with a time-honored tradition of proven value. It is well known that a large number of medical advances have stemmed, often unexpectedly, from investigations aimed primarily at a further understanding of the living world, without any defined practical objective.

2. Respect for the freedom of the investigator, a logical corollary to the preceding principle. Considering that the outcome of basic research cannot be predicted, much less its possible applications, the choice of subject is best left to the investigators-within the limits of the Institute's objectives and resources-on the grounds that researchers are most likely to be creative and productive if allowed to pursue their own interests. The risk of an excessive dispersion of effort is not as great as advocates of a more authoritarian leadership might suspect. Modern biological research relies increasingly on similar approaches and specialized techniques. Under such conditions, working next to a group active in a different area but using the same tools and following the same strategy may actually prove very rewarding.

3. An obligation to help develop beneficial applications whenever the opportunity arises. This commitment, which distinguishes the ICP from centers devoted exclusively to basic research, is mandated by the Institute's specific aims. The translation of findings made in frontline biological research into useful medical applications is best done with the help of the experts who made the findings and possess the required knowledge and skills. At present, virtually every research group at the ICP is engaged in both basic and applied research, the latter often being done in collaboration with clinical investigators or with industrial researchers. 
4. Promoting multidisciplinary collaboration within a critical mass of competences, instruments, and techniques in such fields as structural chemistry, biochemistry, cell biology, genetics, molecular biology, immunology, microbiology, and virology. Proficiency in several of these disciplines is often needed to bring a research project to successful completion and, because of their high degree of specialization, can only be achieved by a cooperative effort. On the other hand, once such a critical mass exists, its resources can be used simultaneously toward the realization of several different projects. The focus has thus changed: instead of the traditional approach in which a high level of expertise in a given area, such as microbial diseases, tropical medicine, or cancer, is brought together and basic disciplines provide only ancillary support, the emphasis has shifted to the core multidisciplinary support as the central prop for a wide spectrum of research activities.

5. An emphasis on the training of young investigators and on helping them achieve independent status. This implies a high turnover of staff. Of the 150-odd investigators working within the Institute (LICR included), only some $40 \%$ have academic positions, half of them tenured (mostly at the university); $20 \%$ are postdoctoral fellows, and $40 \%$ are graduate students. To this end, a vigorous fellowship program has been developed. At present, eight yearly fellowships are awarded on a worldwide, competitive basis. In addition, the Institute has provisions to give a few selected, young investigators the opportunity to develop an autonomous research group, assuring them financial support for up to five years. Considered a high priority, this program is designed to obviate a major drawback of our research system, namely, the obligation to raise one's own grant support. When imposed prematurely, this obligation has stifled many a promising career.

6. A premium on excellence. The activities of ICP researchers are regularly reviewed by specially convened visiting teams, and the overall productivity and policies of the Institute are overseen by an inter-

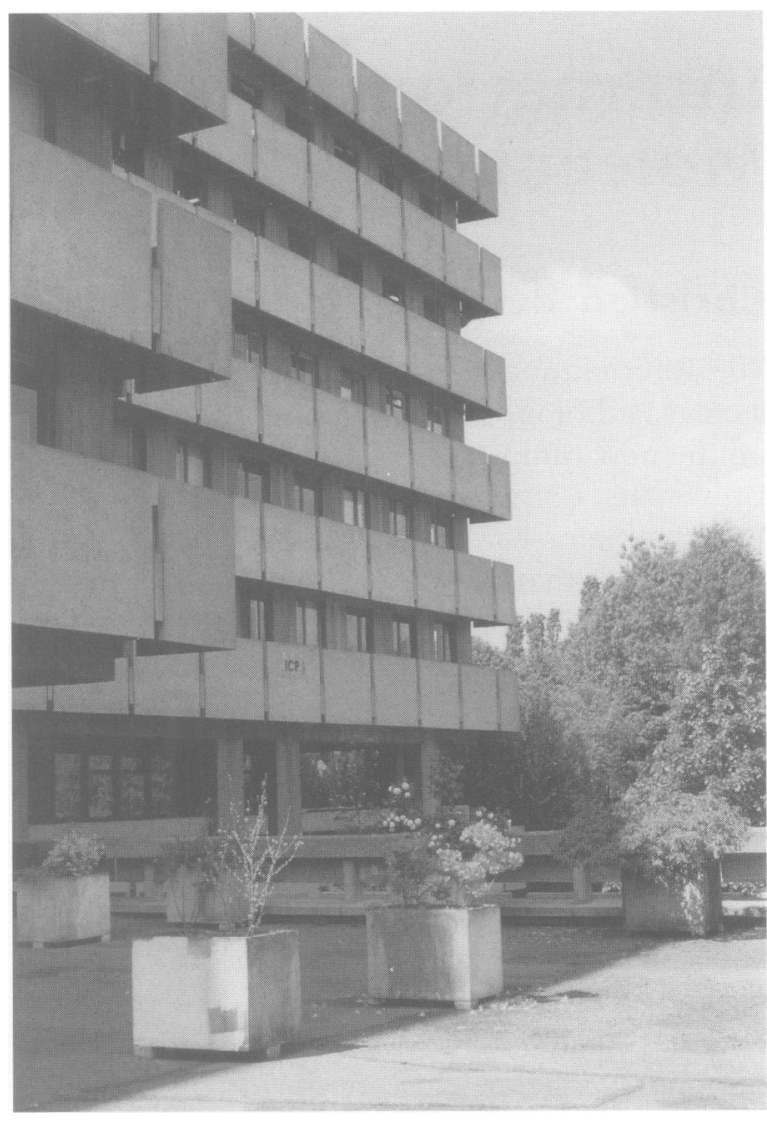

FIG. 1. The International Institute of Cellular and Molecular Pathology in Brussels, Belgium.

national council of four members. Great importance is also given to the quality of the equipment and of the technical and administrative staff (about 100 people altogether).

Unlike its neighbors, Belgium has no provision for the separate funding of centers such as the ICP. Nevertheless, the Institute remains financially healthy, thanks to the support of the parent university, participation in governmentsponsored programs, grants from national and international organizations, contracts with industry, and private philanthropy. Association with a large, fully funded LICR branch is also a major asset.

The ICP strengths lie in the fields of biochemistry, cell biology, microbial and viral pathology, parasitology, immunology, and cancer research, with an emphasis in each area on molecular biological approaches. Biochemical investigations are focused on the enzymatic pathways, tissue-specific expression, physiological regulation, and genetic pathology of carbohydrate and 
purine metabolism. Cell biology research includes studies on the endocytic uptake and intracellular transport and processing of extracellular materials, and on the breakdown and remodeling of connective tissue structures. Among the problems of infectious pathology under investigation are the mechanisms by which Yersinia bacteria invade cells with the help of secreted proteins. Lyme disease, Theiler's virus, and the influence of viral infections on the immune system are also being studied. In parasitology, interest is centered on the glycosome, a cell organelle uniquely present in trypanosomatids, which include the agents of sleeping sickness, Chagas disease, and leishmaniases. The ICP is particularly strong in the field of immunology; it has carried out numerous clinical investigations and experimental studies on the secretion of IgA molecules and their involvement in mucosal immunity. In addition, lymphokines, especially interleukins 6 and 9, are under investigation at the LICR branch, which also has a major group working on the immunological defense against cancer. This group has identified and characterized several tumor-specific antigens now used in the development of new vaccination therapy. Preliminary clinical testings are under way.

Thus, in its modest way, the ICP contributes to the new form of biomedical research that endeavors to build new medical advances on an enhanced understanding of fundamental living processes. It also provides a stimulating setting for young investigators wishing to participate in this effort. 